\title{
Citizenship and people with dementia - a case for the ethics of care
}

Tula Brannelly, University of Southampton

\section{Abstract}

The ethics of care is an emerging field of interest in care for people with dementia. The ethics of care as proposed by Joan Tronto (1993 and 2013) brings together a political argument for care alongside a framework to guide and critique practice. This has the significant advantage of recognising inequality as an issue of social justice, and therefore recognition of the fight that people with dementia face to achieve rights and citizenship. The integrity of care enables another set of citizenship practices, that is citizenship as identity and belonging can be achieved by promoting inclusion, not only in care but in defining and creating policy, research and practice.

\section{Citizenship challenges}

There are considerable contentions and significant barriers for people with dementia to maintain citizenship. In this paper, I suggest that an ethics of care (Tronto 1993 and 2013) is a useful lens to untangle three of these contentions and offers alternative possibilities for maintaining citizenship. The ethics of care is a burgeoning area of theoretical and applied interest (Barnes, Brannelly, Ward and Ward 2015) that has been used in diverse fields including international relations, environmentalism and health and social care. There is a paucity of research in the area of dementia, although this field is also growing. The ethics of care lens enables a political, complex and situated examination of the issues faced by certain groups of people, and it offers potential for transformation. In this paper, three citizenship contentions are discussed in relation to people with dementia - citizenship as a relationship between the individual and the state; citizenship as a practice; and citizenship as identity and belonging.

Citizenship is multifaceted, and contested (Humpage 2010, 2008; Lister 2003). It is a set of rights and responsibilities (Marshall 1950, 1981), and a basis for the relationship between individuals and the state. For people with dementia, as for any marginalised group, this relationship foregrounds issues of social justice that include equality - the recognition given to a particular group and the responses available to them to ensure they are able to live as well as possible.

The contention here is that marginalised groups often have to fight to have their rights recognised, as can be seen in the emergent social movements of people with dementia (Bartlett 2014). Older people, and in particular older people with dementia, struggle for recognition of their social worth in an era that overvalues individuality, productivity and youth. The ethics of care seeks to challenge societal norms that position marginalised groups in ways that disadvantage them, and offers critique 
of policy and practice decisions based on these social norms. A key aspect of the ethics of care is the avoidance of oppression.

The second contention is that citizenship is actively practiced (Lewis 1998, Österholm and Hyden 2014). Here, the contention is that the ideal citizen is a person who independently meets their responsibilities and has autonomy. However, this excludes and marginalises all groups of people who are unable to meet this ideal, including young people (Hart 2009), and some people with disabilities. Instead, Lanoix (2007) suggests that citizenship is based on the condition of being human and relational to others.

As a guiding principle in health and social policy, independence is problematic as people live interdependent lives in complex social networks, where networked care involves paid and unpaid caregivers (Barnes 2015). The status given to independence and autonomy reinforces inability where capacity is lost, which holds little reality to how people make decisions about themselves and their loved ones in their lives. If decision making is considered relational rather than individual and selfdetermined then the emphasis on loss is minimised and relational decision making becomes the objective.

Inclusion of people with dementia in decisions about their care remain the responsibility of care providers (Brannelly 2006). The ethics of care challenges the dichotomy of dependence and independence in recognition of the role of care that we all give and receive in our lives, favouring instead that all humans are interdependent. It is impossible to reach adulthood without care, and we need elevated levels of care form others when experiencing vulnerability (Tronto 1993).

Another aspect of citizenship is that it is a sense of identity and belonging in communities (Stevenson 2003, Jones 1994). The third contention is that maintaining identity and remaining in communities is not the focus of meeting needs as services elevate the assessment and avoidance of risk (Bailey, Clarke, Gibb et al 2013) at odds with what people with dementia and their families may want from care providers. People with dementia have long biographies of involvement in their communities and the fulfilment of roles through work and family, caring for other and receiving care. Understanding responses offered by care providers to support people within their relational lives is possible through the integrity of care analysis offered by the ethics of care (Tronto 1993 and 2013).

In this paper, I discuss these three aspects in turn. First, the political positioning of people with dementia is discussed alongside the marginalisation and exclusions that are experienced in order to consider what political responses are required. This is a sketch of the issues facing people with 
dementia and their families, and the ways that care are currently organised to meet need. Second, the practice of citizenship is currently hampered because dependence is associated with protection rather than the active citizenship of involvement and this is discussed in relation to the way policy influences practice. Thirdly, the integrity of care is described as a means for promoting active citizenship as a practice by centralising the experiences of people giving and receiving care (Tronto 1993 and 2013).

\section{Citizenship, social justice and the ethics of care}

'Citizens are not equal by virtue of being declared equal, but through an elaborate social process through which they become equal' (Tronto, 2013, p120).

The ethics of care is a way of thinking about the world, in which complex interdependencies are borne out through relationships between people (Tronto 1993), a counter current to the dominant neoliberal discourse that overvalues individualistic, self-autonomous and self-interested actions (Tronto 2013, Barnes, Brannelly, Ward and Ward 2015). Recent developments in the ethics of care (Tronto 2013, Barnes 2012) have called for a reconnect with the political feminist concerns of care ethics such as equality, justice and the avoidance of domination (Tronto 2013, Barnes, Brannelly, Ward and Ward, 2015). In this section a brief overview is provided of the political aspirations of care ethics, the definition of care provided by Tronto and Fisher (1993) and the integrity of care that can guide and critique care practices.

In order to move toward social justice, recognition is required of the inequalities faced by particular social groups. The ethics of care seeks out those injustices by knowing the experiences of those who live them, and examines potential avenues of renewal. Micro level analysis provided by qualitative methodologies of the experiences of the social group enable a detailed and informed response to addressing injustice, bringing together multiple layered analyses to inform and understand how to make life more tolerable in difficult circumstances.

Tronto (1993) in her book Moral Boundaries, converged care and politics. Care is defined as (1993, p 103):

On the most general level we suggest that caring can be viewed as a species activity that includes everything we do to maintain, continue and repair our 'world' so that we can live in it as well as possible. That world includes our bodies, ourselves and our environment, all of which we seek to interweave in a complex, life-sustaining web

This definition is intentionally broad, inclusive and relational to reflect the significance given to interdependence in the ethics of care - that all humans are dependent on care and all human give 
care. Interdependence underpins the integrity of care to avoid individualised prioritisation of need and looks to acknowledge the needs of all involved in providing care.

\section{The integrity of care}

The integrity of care was developed by Tronto in 1993 and added to by Sevenhuijsen (1998) as a way of critiquing and guiding caring practices. It initially had four phases - attentiveness, responsibility, competence and responsiveness, with a fifth added, solidarity in 2013. Sevenhuijsen added trust as an essential component in relationships. Care practices are relational and include the involvement of formal care providers alongside others involved in care. When services become involved and care networks are opened up to assessment and subsequent interventions, service providers need to understand how care operates within the network to support it (Brannelly 2015). Understanding needs includes those of the person seen as the primary care -receiver alongside the needs of others including those providing services. The phases of caring are:

- Caring about. Attentiveness. At this first phase of care, someone or some group notices unmet caring needs. If attentiveness is not present then the other elements of care ethics cannot be practiced. Openness, recognition, respect for identity and diversity are required. In care situations the needs of all are noted, and the course of action taken can be measured against these to understand whose needs have been met.

- Caring for. Responsibility. Once needs are identified, someone or some group has to take responsibility to make certain that these needs are met. Assuming responsibility to act on the basis of the needs identified in attentiveness requires 'judging with care'. Attempting to meet needs but not actually meeting needs indicates a failure of responsibility.

- Care-giving. Competence. The third phase of caring requires that the actual care-giving work be done. Requires allocation of resources and access to services.

- Care-receiving. Responsiveness. Once care work is done, there will be a response from the person, thing, group, animal, plant or environment that has been cared for. Observing that response and making judgements about it (for example, was the care sufficient, successful, complete?) is the fourth phase of care. Note that while the care-receiver may be the one who responds, it need not be so. Sometimes the care-receiver cannot respond. Others in any particular care setting will also be in a position, potentially, to assess the effectiveness of the caring act(s). And, in having met previous caring needs, new needs will undoubtedly arise.

- Caring with. Solidarity. This final phase of care requires that caring needs and the ways in which they are met need to be consistent with democratic commitments to justice, equality and freedom for all. Trusting and empathetic relationships are required. 
In the next section of this paper, the citizenship contentions are discussed underpinned by the principles of the ethics of care.

\section{Equality and social justice}

As citizenship is predicated on social justice, it is fitting to examine the inequalities that currently influence the experience of dementia. These include issues of gender, socioeconomics and resource allocation.

Erol, Brooker, and Peel (2015) identified that women are disproportionately affected by dementia as they live longer, they are more likely to experience dementia, women are more often unpaid carers for others, or in low paid care work in residential settings. Evidence is emerging regarding the gender and 'race' differences in the experience of dementia (Botsford, Clarke and Gibb 2011). In the United States, there are higher rates of dementia among older black people than white people, for which socioeconomic status is recognised as a risk factor (Yaffe et al 2013). Russ et al (2013) found a link between early school leaving age and the development of dementia in women, also attributed to lower social class. More generally, older women face financial hardship in older age, not having had work pensions, which is significant when state service provision is shrinking, such as in the UK.

The provision of care for people with dementia has raised significant issues about the types, organisation and quality of care available to people with dementia and their families, locally and globally. This constitutes an issue of 'public and political concern whose social dynamics operate at local, national and transnational levels' (Williams 2001, p. 487). Access to services, getting the right level of service at the right time to support the needs of the person with dementia and their family are key to living well with dementia.

In these times of austerity, it is clear the financial hardships associated with inequalities in health are exacerbated (Arber, Fenn and Meadows 2014). Access to services has diminished, and there is an increased expectation of people resourcing their service use. Emphasis on self-care and self-funded options for care are a concern for the citizenship of people who are less well-resourced to meet the costs of their own care. Older people living in poverty are already priced out of retirement housing, the benefits of which allow for people to plan to increase the help they may need as they age (Aldridge, Kenway and Pannell 2012). Equality of provision is essential to ensure acceptable services that are not a threat to the wellbeing of people with dementia, nor a concern to their families.

Pressures on social care for older people with dementia are prevalent. Lewis and West (2014) noted the increasing need for service provision due to the changing demography and less available informal care due to employment happening in (previously known as ) western countries. IN the UK, 
eighty per cent of people in residential care have dementia, indicating increased and complex needs. Funding for social care has always been constrained, with staff paid poorly for work that is often emotionally and physically demanding, and difficult to do well. This political landscape of care calls for serious reconsideration of the implications for citizenship of older people, as Lymbery (2010) suggests the inadequate resourcing for adult social care is most significant.

\section{Interdependence}

The ethics of care provides a significant challenge to the emphasis placed on independence and dependence, favouring interdependence as a way of viewing the need for all people to give and receive care. As Lloyd states 'The value of an ethics of care perspective is that it does not differentiate between old (dependent) and young (independent) but sees dependency as inherent within the entire lifecourse and thus overcomes the tendency to regard older people as 'the other' (Lloyd, 2010, p 4). Dependence is often pathologised, and with it, passivity is reinforced (Tronto 2013).

Interdependence signifies the way that people make decisions about their lives, in relational autonomy (MacKenzie and Stoljar, 2000). People are categorised as care givers or care receivers, a construction of the welfare subject that freezes identity in a way that is neither true nor particularly helpful (Ward 2011). A person is denoted as a carer or a receiver of care, when in fact they may be both. Because we are vulnerable, does not mean that we do not provide care to others.

In health and social policy, independent people are offered 'choice and control' and dependent people are offered 'care and protection' (Barnes 2012). Any sign of dependence in this dichotomy positions people with dementia as de-authorised (Young 2011), passive and unable to contribute. Emphasis on independence reinforces individual autonomy, to be tested and denied to constitute a group who can be 'done to', reinforcing exclusion and denying citizenship.

If people are simply judged as unable to make decisions about their lives, the most basic of human rights are contravened - a person may be detained, or given treatment against their will (Drew et al 2011). To borrow from a discussion about similar issues in mental health service provision (Brannelly 2015), if human rights that constitute the taken for granted ascription of citizenship are removed, then the attribution of citizenship per se, is in practice, conditional on mental state as defined by clinical services. Individual 'rights to' are eclipsed by institutional 'control of' and 'control of' is, at least for some, experienced as oppression (Brannelly 2006, Owen and Floyd, 2010).

Choice is required throughout caring experiences for people with dementia and their families, to make decisions about what fits their needs. This includes how the response to care is anticipated and experienced, and what actually happens when care is provided. Having control means that 
choices can be reviewed and decisions revised. That this is practiced following the integrity of care means that these changes to care practices are realised.

The need for protection is acknowledged as required in the face of a life-threatening risk that requires immediate action in the short term, until a longer term solution is found. Protection needs to be stated and understood as practices that impinge on human rights, that people may well object to protection on those grounds, and therefore that the reaction of the care receiver to care provided needs to be understood in these terms. Even when protection is necessary, people are still able to be given choice and control to influence elements of practice so that they are more consistent with their wishes and those of their family.

Work of this kind is based in a relationship in which there is an understanding of the people and their relationships, the messy complexity of life. Choice, control, care and protection require dialogic care, a longstanding conversation about the experiences of life in distressing circumstances for which it is necessary to make the best of an unsatisfactory situation, or as (Kittay 1999, p157) states 'dialogic care without words'.

\section{The possibilities of the integrity of care for active citizenship}

Fortunately, the current emphasis is on avoiding oppressive experiences. More recently, people with dementia have been reconstructed as active citizens with human and social rights (Bartlett and O'Connor 2007, 2010), an evolving practice that is historically and socially situated (Nedlund and Jonas 2015). In terms of identity and belonging as a citizen, social care is essential in maintaining ties to enable wellbeing and reciprocity. Accordingly, supportive social care is underway. In the UK, peer support is emerging through the National Dementia Strategy (Keyes et al 2014) in line with what is available to others with disabilities. Care networks are recognised as essential supports that enable people with dementia to live well (Ward, Howorth, Wilkinson et al 2011), and community based initiatives that promote inclusion.

Care practices are relational, and opportunities arise for various forms of practice that may uphold rights, sustain citizenship or may conversely be a cause of oppression. As one of the central tenets of an ethics of care is to avoid domination and the experience of oppression, some form of guidance for practice is welcome. That guidance is available using the integrity of care.

The invisibility that has historically been attached to a diagnosis of dementia has meant that people with dementia have been rendered invisible in health and social care decisions. Attentiveness requires that the needs of all in the care collective are acknowledged in order to understand how to proceed with care in order to meet those needs. If meeting the needs of all involved in not possible due to direct conflict, then other measures are required to address these conflicts. Attentiveness can 
also review care to see whose needs are met through the decisions taken. An example may be that a practitioner believes that a daughter is overburdened looking after her father at home and considers residential care as the correct placement, while the family are willing to continue as they are. If a decision is to place the person with dementia in residential care, it is the needs of the practitioner that are met through this plan. If the person remains at home with increased care provision to help the daughter provide care, then the needs of the person with dementia and the daughter are met.

Attentiveness can be practiced with or without the direct involvement of the person with dementia. If the person is unable to contribute to the discussion then additional care is needed to consider the potential impacts of the decisions that are made, and additional attention paid to how the person with dementia responds to care changes. Responsiveness enables care to be reviewed according to the preferences of the person and care activities altered and reviewed to meet needs better.

The ethics of care recognises the vulnerability of the care receiver in the care collective, and calls for particular attention to be paid to their needs. In the care collective, paid carers often do not state their needs explicitly, which would help people understand the processes through which protective decisions are made.

In the ethics of care competence is about the ability to meet needs once they have been identified, and responsibility to meet needs ensures that those needs are met. Having the right resources is key to being able to meet needs. One aspect of care that is crucial for people with dementia is care staff having the right amount of time to spend with the person to ensure that needs are met. Take for example in England, the work of domiciliary care workers who are expected to spend a maximum of 15 or 20 minutes with a person to complete daily care. This has been widely criticised as woefully inadequate. An ethics of care perspective would be that this is an advocacy issue for resources to help people do their caring activities well.

The addition of solidarity in $\mathbf{2 0 1 3}$ was welcome as it grounds the aim of care provision as aligned with the aspirations of people with dementia - that is to remain and belong in communities to, in total or part, fulfil their roles that give them meaning in everyday life. This is a connection to a place and people and enables people to have a sense of identity and belonging that is so critical in maintaining citizenship and avoiding exclusion.

\section{An ethics of care for people with dementia}

Further consideration is required to provide more nuanced understanding of the inequalities and social justice issues faced by people with dementia. Recognition of vulnerability means that additional rights are required for people with dementia in order to address not only discriminations that are currently faced, but to improve the situation of people with dementia in need of care. Care 
decisions made in the context of shared decision-making avoid reinforcing inability and prioritising one set of care needs over another and promotes active citizenship.

Swaffer (2015) described 'prescribed disengagement' where she was given well-meaning but misguided advice about how to conduct her life post diagnosis. She was advised to live a quiet and non-challenging life, an antithesis to living well with dementia and to maintaining citizenship. An ethics of care analysis would distinguish that it is the responsibility of society to create the space and place for people with dementia to contribute, consistent with a social citizenship approach.

User involvement requires organisations that support people who use services and are able to recognise need at a personal level alongside the need to promote political action to make change. This approach is consistent with democratic cultural pluralism (Young 2011); identity based politics brought to the fore by a myriad of social groups to create change. Activism of this kind are acts of citizenship (Bartlett 2014, Isin 2008) where people with particular experiences are politically engaged to make the kinds of changes for future service users that they desire. The integrity of care can be used to guide participation of people with dementia by being attentive to the motivations for participation, responsible to those aims and ensuring those facilitating participation are equipped to do so (Barnes, Brannelly, Ward and Ward 2015).

Substantial movements have changed the landscape of the experience of dementia markedly. People with dementia tell us that those movements have not yet gone far enough (Swaffer 2015); more involvement of people with dementia in policy making, research and practice development is required (McCabe and Ellis Bradley 2012). Swaffer's editorial (2015) describes another pertinent aspect of living with dementia; that the diagnosis and service provision form a part of life, but are not life itself. People with dementia have various strengths and challenges that influence how they navigate the uncertainties of their impairments, alongside the caring relationships in which they are embedded. Part of that history may well be levels of inclusion or marginalisation that shape the experience of older age and/or living with dementia. Part of the challenge to care providers is working with these intricacies, and responding well to older people in a way that connects with and makes people feel cared for and accept service provision that meets needs.

The ethics of care is a way of thinking about the world that brings together issues of societal marginalisation and inequality alongside guidance for practice. When considering the future of services for people with dementia and how to promote citizenship that frames rights based approaches alongside justice and care, the ethics of care creates the space for the personal and political to be considered together for meaningful renewal and change. 
Acknowledgement. Thanks to the reviewers of an earlier version of this article and to Ruth Bartlett for helpful comments.

References

Aldridge H, Kenway P and Pannell J, (2012) Who can afford retirement housing? York, Joseph Rowntree Foundation.

Arber, S., Fenn K, Meadows R. (2014). Subjective financial well-being, income and health inequalities in mid and later life in Britain. Social Science and Medicine 100: 12-20. DOI:

10.1016/j.socscimed.2013.10.016

Bailey C, Clarke CL , Gibb C, Haining S, Wilkinson H and Tiplady S. (2013) Risky and resilient life with dementia: review of and reflections on the literature, Health, Risk \& Society, 15:5, 390-401, DOI: $10.1080 / 13698575.2013 .821460$

Barnes M (2012) Care in Everyday Life, Policy Press, Bristol.

Barnes M, Brannelly T, Ward L and Ward N (2015) (Eds) Ethics of Care, Critical Advances in International Perspective, Policy Press, Bristol.

Bartlett R (2014), Citizenship in action: the lived experiences if citizens with dementia who campaign for social change. Disability and Society, 29:8, 1291 - 1304, DOI 10.1080/09687599.2014.924905

Bartlett R and O'Connor D (2010), Broadening the Dementia Debate: Toward social citizenship, Policy Press, Bristol.

Botsford J., Clarke C.L. and Gibb C.E. (2012) Dementia and relationships: experiences of partners in minority ethnic communities. Journal of Advanced Nursing 68(10), 2207-2217. doi: 10.1111/j.13652648.2011.05905.x

Brannelly T. (2006), Negotiating ethics in dementia care: An analysis of an ethic of care in practice." Dementia 5(2): 197-212.

Brannelly T (2015), Mental health service use and the ethics of care: in pursuit of justice, in Barnes M, Brannelly T, Ward L and Ward N (2015) (Eds) Ethics of Care, Critical Advances in International Perspective, Policy Press, Bristol.

Drew, N., Funk M, Tang S et al. (2011). Human rights violations of people with mental and psychosocial disabilities: an unresolved global crisis. The Lancet 378(9803): 1664-1675. 
Erol R, Brooker D, Peel E. (2015), Women and Dementia, A Global Review, London, Alzheimer's Disease International.

Hart S. (2009), The 'problem' with youth: young people, citizenship and the community. Citizenship Studies, 13: 6, $641-657$.

Humpage L (2010), New Zealand Attitudes to Social Citizenship in the context of Neoliberalism, Executive Summary, Department of Sociology, University of Auckland.

Humpage L. (2008), Talking about citizenship in New Zealand, Kōtuitui: New Zealand Journal of Social Sciences Online, Vol. 3: 121-134, doi: 1177-083X/08/0302-0121.

Isin E (2008) Theorising Acts of Citizenship, in Isin E and Nielsen G.M. (2008) Acts of Citizenship, Zed Books, New York.

Jones K. (1994) The Making of Social Policy in Britain, 1830 - 1990, second edition, London, Athlone Press.

Kittay E.F. (1999), Love's Labor. Essays on Women, Equality and Dependency. London and New York: Routledge.

Lanoix, M. (2007), The Citizen in Question. Hypatia, 22(4), 113 - 129.

Lewis, G. (1998), Citizenship. In G. Hughes (Ed.), Imagining welfare futures (pp. 103 - 150). London: Routledge/Open University Press.

Lewis, J. and A. West (2013). Re-Shaping Social Care Services for Older People in England: Policy Development and the Problem of Achieving 'Good Care'. Journal of Social Policy 43(01): 1-18.

Lister R. (2003), Citizenship: Feminist Perspectives. Basingstoke: Macmillan.

Lloyd, L. (2010). The Individual in Social Care: The Ethics of Care and the 'Personalisation Agenda' in Services for Older People in England. Ethics and Social Welfare 4(2): 188-200.

Lymbery, M. (2010). A new vision for adult social care? Continuities and change in the care of older people. Critical Social Policy 30(1): 5-26.

Mackenzie, C. and N. Stoljar, Eds. (2000). Relational Autonomy: Feminist Perspectives on Autonomy, Agency and the Social Self. Oxford, Oxford University Press.

Marshall, T.H. (1950), Citizenship and Social Class. Cambridge: Cambridge University Press.

Marshall, T.H., (1981). The right to welfare and other essays. London: Heinemann. 
McCabe L \& Ellis Bradley B (2012) Supporting User Participation in Local Policy Development: The Fife Dementia Strategy, Social Policy and Society, 11 (2), pp. 157-169. DOI:

$10.1017 /$ S1474746411000558

Owen, J. L. and M. Floyd (2010). Negotiated Coercion: Thoughts about Involuntary Treatment in Mental Health. Ethics and Social Welfare 4(3): 297-299.

Österholm JH and Hyden LC (2014), Citizenship as practice: Handling communication problems in encounters between persons with dementia and social workers, Dementia, DOI:

$10.1177 / 1471301214563959$.

Russ, T. C., E. Stamatakis, M. Hamer, J. M. Starr, M. Kivimaki and G. D. Batty (2013). Socioeconomic status as a risk factor for dementia death: individual participant meta-analysis of 86508 men and women from the UK. British Journal of Psychiatry 203(1): 10-17.

Sevenhuijsen, S. (1998) Citizenship and the Ethics of Care. Feminist Considerations on Justice, Morality and Politics. London and New York: Routledge.

Swaffer, K. (2015). Dementia and Prescribed Dis-engagement. Dementia 14(1): 3-6.

Stevenson N. (2003), Cultural Citizenship. Cosmopolitan questions, issues in media and cultural studies, London: Open University Press.

Tronto J.T. (1993), Moral Boundaries. A political argument for an Ethic of Care. London: Routledge. Tronto J.T (2013), Caring Democracy. Markets, Equality and Justice. New York and London: New York University Press.

Yaffe, K., C. Falvey, T. Harris, A. Newman, S. Satterfield, A. Koster, H. Ayonayon, E. Simonsick and A. Kaup (2013). Do socioeconomic disparities explain higher dementia incidence among black older adults? Alzheimer's \& Dementia 9(4): P343-P344.

Ward, N. (2011). Care Ethics and Carers with Learning Disabilities: A Challenge to Dependence and Paternalism. Ethics and Social Welfare 5(2): 168-180.

Ward R, Howorth M, Wilkinson H, Campbell S and Keady J (2011), Supporting the friendships of people with dementia, Dementia, 11(3) 287-303, DOI: 10.1177/1471301211421064

Williams, F 2001, In and beyond New Labour: Towards a new political ethics of care, Critical Social Policy, vol. 21, no. 4, pp. 467-493.

Young, I. M. (2011) Justice and the Politics of Difference, New York: Princeton University Press. 